\title{
CONTROLE TECNOLÓGICO DO CORPO E DA VIDA: CESARIANA ENTRE MULHERES USUÁRIAS DO SETOR PRIVADO
}

\author{
CONTROL TECNOLÓGICO DEL CUERPO Y LA VIDA: \\ CESARIANA ENTRE MUJERES USUARIAS DEL SECTOR PRIVADO \\ TECHNOLOGICAL CONTROL OF THE HUMAN BODY AND LIFE: \\ C-SECTION AMONG WOMEN PRIVATE SECTOR USERS
}

\author{
Liana Riscado ${ }^{1}$, Claudia Bonan ${ }^{1}$, Regina Simões-Barbosa ${ }^{2}$ e \\ Andreza Rodrigues ${ }^{2}$
}

${ }^{1}$ Fundação Oswaldo Cruz, Rio de Janeiro/RJ, Brasil

${ }^{2}$ Universidade Federal do Rio de Janeiro, Rio de Janeiro/RJ, Brasil

\begin{abstract}
RESUMO: O artigo analisa os sentidos que a ideia de controle do corpo e da vida adquire nos discursos acerca da decisão sobre o parto, a partir das falas de mulheres que realizaram cirurgia cesariana em maternidades privadas da região metropolitana do Rio de Janeiro e do município de São Paulo. A abordagem teórico-metodológica é da análise das práticas discursivas e produção de sentidos. Dor, integridade corporal, controle dos riscos, estética do parto e os tempos (social e reprodutivo) são acionados como elementos contidos no ideário de controle que circunda a cesárea como uma prática de nascimento. Esse controle seria exercido em redes de interações entre mulheres, familiares, profissionais, objetos tecnológicos médicos e não médicos e instituições.
\end{abstract}

PALAVRAS-CHAVE: Parto; Cesárea; Controle; Dor; Corpo.

RESUMEN: El artículo analiza los sentidos que la idea de control del cuerpo y de la vida adquiere en los discursos acerca de la decisión sobre el parto a partir de las palabras de mujeres que realizaron cirugía cesárea en maternidades privadas de la región metropolitana de Río de Janeiro y del municipio de São Paulo. El enfoque teórico-metodológico es del análisis de las prácticas discursivas y la producción de sentidos. El dolor, integridad corporal, control de los riesgos, estética del parto y los tiempos (social y reproductivo) son accionados como elementos contenidos em el ideario de control que circunda la cesárea como una práctica de nacimiento. Este control se ejerceren redes de interacción entre mujeres, familiares, profesionales, objetos tecnológicos médicos y no médicos, e instituciones.

PALABRAS CLAVE: Parto; Cesárea; Control; Dolor; Cuerpo.

ABSTRACT: This paper analyses the way that the idea of control of body and life gets in the discourse about the decision on childbirth from the speech of women who underwent cesarean surgery in private hospitals in the metropolitan area of Rio de Janeiro and São Paulo. The theoretical-methodological approach is the analysis of discursive practices and the production of meanings. Pain, body integrity, risk control, birth aesthetics and times (social and reproductive) are triggered as elements contained in the control idea that surrounds cesarean delivery as a birth practice. This control would be exercised in interaction networks among women, family, professional, medical and non-medical technological objects, and institutions.

KEYWORDS: Parturition; Cesarean Section; Control Pain; Body. 


\section{Introdução}

O Brasil se destaca no cenário mundial com mais da metade dos nascimentos sendo realizados através de cesariana, embora a Organização Mundial de Saúde (OMS) aponte valores entre 10 e $15 \%$ para o procedimento como mais recomendável (WHO, 2015). No setor privado de saúde, responsável por cerca de $25 \%$ do total de nascimentos (Victora et al., 2011), no ano de 2017, 85\% desses se realizaram por meio de cesariana (Beogo, Rojas, \& Gagnon, 2017; Victora et al., 2011; Domingues et al., 2014). As usuárias desse setor de saúde são, principalmente, mulheres das classes com renda e escolaridade mais elevadas. Nessas camadas, encontram-se modos próprios de lidar com as tecnologias médicas e de se relacionar com os serviços e profissionais de saúde (Barros et al., 2011; Cesar, Mano, Carlotto, Gonzalez-Chica, \& Memdoza-Sassi, 2011 ). Segundo Sanabria (2010), mulheres de classes médias brasileiras consomem tecnologias médicas bastante sofisticadas e o atendimento no setor privado é personalizado e diferenciado, refletindo valores e desejos de um sistema ideológico individualista, em que há uma obrigação moral no cuidado com a própria saúde e com o melhoramento de si, caracterizando uma biopolítica do self(Rose, 2013). Em nosso país, a cesárea pode ser pensada como uma prática atravessada por essa forma de gerir o corpo e a vida?

Como contribuição para esse campo de conhecimentos e visando explorar outras perspectivas de análise para a problemática das altas taxas de cesariana no setor suplementar de saúde, empreendemos um estudo sobre experiências de parto e de nascimento, em contextos de largo uso de intervenções médico-tecnológicas, como são as maternidades privadas das grandes capitais brasileiras. Partimos da premissa que o incremento da prática da cirurgia pode ser um caso esclarecedor das transformações societárias, ainda em curso, que expressam modos específicos dos processos de biomedicalização (Clarke, Fishman, Fosket, Mamo, \& Shim, 2010), de biopoder e de biopolítica (Foucault, 1976/1985; Rose, 2013). Consideramos tais processos aliados à pastoral do empreendimento de si do neoliberalismo tardio (Dardot \& Laval, 2016), que acontecem no Brasil contemporâneo, onde principalmente as camadas sociais privilegiadas aspiram a um crescente controle tecnológico do corpo e da vida, em suas várias dimensões.

Neste artigo, apresentamos os resultados do estudo citado acima, que teve como objetivo compreender os sentidos do controle tecnológico do corpo e da vida envolvidos nos processos de decisão sobre o parto e o nascimento, a partir de discursos de mulheres que realizaram cirurgia cesariana em maternidades privadas do Rio de Janeiro e de São Paulo.

\section{Metodologia}

A abordagem teórico-metodológica adotada neste estudo é a análise de práticas discursivas e produção de sentidos. Para Spink e Medrado (2013, p. 26), práticas discursivas devem ser definidas "como linguagem em ação, ou seja, as maneiras a partir das quais as pessoas produzem sentidos e se posicionam em relações sociais cotidianas". 
As participantes do estudo são mulheres que compõem uma subamostra da pesquisa "Itinerários terapêuticos e a construção da decisão pelo parto cesáreo" (Bonan, 201311), desenvolvida entre 2010 e 2013. Na referida pesquisa, foram entrevistadas 77 mulheres com idade entre 18 e 35 anos, que realizaram cesarianas na região metropolitana do Rio de Janeiro e no município de São Paulo, no ano de 2011, em serviços públicos, privados e conveniados com o SUS. As mulheres foram captadas no banco de dados da pesquisa “Nascer no Brasil - Inquérito Nacional sobre Parto e Nascimento" (Leal et al., 2012), utilizando como adaptações os critérios de Robson (2001), para compor uma amostra de mulheres cujas condições clínicas e/ou obstétricas não representariam uma indicação médica absoluta de cesariana e, assim, investigar motivações não clínicas ou obstétricas para a realização da cirurgia. Após contato telefônico com o grupo elegível, foi composta uma amostra de 42 mulheres que haviam realizado cesariana em maternidades privadas e aceitaram participar do estudo. O tempo transcorrido entre a data do parto e a data da entrevista variou de 4 a 18 meses.

As informações foram coletadas por meio de entrevistas abertas em profundidade (Minayo, 2010), conduzidas por quatro pesquisadoras e realizadas nas próprias residências das mulheres. Esses encontros tiveram duração entre 30 e 90 minutos. Utilizou-se uma pauta temática que incluiu história da última gestação e dos cuidados de pré-natal, parto e puerpério, a história das gravidezes e partos anteriores, a história das gravidezes e partos na família e no círculo de amizades, a história afetivo-sexual e de cuidados com a saúde sexual e reprodutiva. As falas foram gravadas em áudio digital e posteriormente transcritas na íntegra por uma profissional contratada.

O processo de análise compreendeu leituras livres das entrevistas. Na medida em que os núcleos temáticos emergiam - dor e sofrimento, integridade corporal, riscos de adoecimento e morte, impressões e expressões estéticas do parto, a organização do ritual social do nascimento, planejamento e articulação entre vida reprodutiva e produtiva -, foram construídos quadros para organizar os discursos das mulheres.

O estudo seguiu as normas de pesquisas com seres humanos, estabelecidas pela Resolução n. 466/12, foi submetido ao Comitê de Ética em Pesquisa do Instituto Fernandes Figueira/Fiocruz, e obteve autorização sob o número CAAE 36529714.2.0000.5269. As mulheres entrevistadas assinaram um Termo de Consentimento Livre e Esclarecido (TCLE), no qual consentiam a participação na pesquisa. Preservou-se o anonimato das participantes atribuindo-as um nome fictício.

\section{Resultados e Discussão}

As mulheres entrevistadas têm uma média de idade de 30 anos. Quase todas vivem com companheiro, possuem nível de ensino superior, exercem profissões liberais, têm rendas compatíveis com as classes médias e altas, e vivem em centros urbanos. A maioria tem filhos (um ou dois), sendo que os nascimentos dos primeiros filhos foram, geralmente, através de cesarianas. No universo das 42 mulheres, poucas tinham experiência prévia com parto vaginal.

Após esta breve caracterização do perfil das mulheres participantes do estudo, apresentamos os resultados em tópicos, organizados segundo os principais núcleos temáticos que emergiram no processo de análise. 


\section{A desnecessidade da dor}

A representação do parto vaginal como doloroso e a ideia da cesariana como algo capaz de ludibriar a dor do parto e mitigar o medo de "sofrer", já demonstrados em outros estudos (Cherniak \& Fisher, 2008; Pereira, Franco, \& Baldin, 2011a; Pereira, Franco \& Baldin, $2011 \mathrm{~b})$, também aparecem no universo estudado:

[Para um parto vaginal é preciso] coragem, coragem de sentir muita dor. Eu sou fresca demais. Então, eu sei que é o tipo da coisa que não combina comigo. (Joana)

Dor, dor, dor [parto normal]. Que é uma dor que eu não conheço, né? Não tive. Aí dizem que é uma dor insuportável. Mas depois que nasce acaba tudo também, né? Que elas falaram. (Vera)

Tanto que as experiências que eu ouvi lá das minhas cunhadas, elas tiveram que fazer parto normal. E é isso, era descrição de sofrimento. (Monica)

A refutação da dor do parto como algo natural e inevitável e a ideia de que se esquivar da dor é um direito básico são temas discutidos na literatura (Cherniak \& Fisher, 2008). Mulheres e médicos compartilham a visão de que, com a "evolução" da cirurgia cesariana, "hoje em dia” não seria mais necessário passar pelo sofrimento do parto. A disponibilidade de tecnologias analgésicas, anestésicas e cirúrgicas, entre o grupo de mulheres pesquisadas, usuárias do setor privado, abre mais do que uma possibilidade, cria uma desnecessidade ou mesmo um novo direito: o de não sentir dor.

Por isso que eu falei para você, no auge da tecnologia do século XXI, não tem necessidade das pessoas terem filho como se tinha antigamente. Hoje em dia a cesárea está muito evoluída, muito evoluída. (Ana)

Aí, quando eu fui nesse primeiro médico, na primeira consulta, ele já falou para mim: 'Olha! Não tem necessidade de você passar por sofrimento nenhum, vamos fazer cesárea’. (Fabiana)

Ele [obstetra] me indicou [a cesárea]. Ele falou que era a melhor coisa, que mulher não foi feita para sofrer daquele jeito. Foi isso. (Regina)

Para muitas mulheres do estudo, o corpo da "mulher de hoje" - implicitamente, aquelas pertencentes às classes de maior renda e escolaridade - tem uma suscetibilidade diferente à dor e, cada vez mais, o parto vaginal parece se distanciar do considerado "normal". Como sugere o depoimento a seguir, há rupturas com ideias de naturalidade e normalidade relacionadas a processos corporais fisiológicos e uma naturalização e normalização da intervenção tecnológica nos processos corporais, ou seja, do corpo operado tecnicamente de fora.

E a gente é menos preparada para ter parto normal hoje, do que era 50 anos atrás. Fazemos muito menos esforço físico no dia a dia, então a dor de um parto normal é muito maior hoje, eu acho, do que era antigamente. Porque antigamente ficava abaixada pra lavar roupa, lavava roupa no rio abaixada. Então aquilo era normal, aquele movimento, aquele processo todo era normal. Hoje eu acho cada dia mais distante a normalidade de um parto natural para as pessoas do que de uma cesárea. (Carla) 
Estar anestesiada aparece como sinônimo de ser "bem cuidada" e de segurança, na fala de uma mulher, e "não sentir nada" é sinônimo de parto seguro, na fala de outra:

Não, estou fora, Deus me livre! Sentir dor, eu estou fora. É o que eu estou falando para você, eu já expeli quatro cálculos renais [compara com dor de parto], e aquela dor toda eu já senti. Então quando eu penso em sentir essa dor de novo, eu não quero, não quero mesmo! Estou fora, eu quero anestesia! Eu quero ser bem cuidada! (Ana)

O parto seguro é o parto realmente onde você não sinta dor, não sinta nada, que é o que eu estava prezando na época, não queria sentir dor nenhuma, e é um parto que está ali para cuidar de você, tirar o seu filho com saúde, com todos os cuidados. (Amanda)

Embora muito difundidos entre as mulheres escutadas na pesquisa, esses sentidos e valores atribuídos aos processos fisiológicos e às intervenções tecnológicas relacionados ao parto e ao nascimento não devem ser generalizados. Estudos com outros grupos mostram a variabilidade das subculturas que rodeiam essas experiências. Mulheres de classes médias e altas estudadas por Carneiro (2015) significam e valorizam positivamente o processo de parir e a dor e o descontrole que lhe seriam inerentes. Outras pesquisas, realizadas com mulheres no SUS, apontaram a visão da dor do parto como algo natural ao processo de parturição e, de certa maneira, algo que se deve suportar (Almeida, Medeiros, \& Souza, 2012; Hotimsky, Rattner, Venancio, Bógus, \& Miranda, 2002; McCallum \& Reis, 2006).

As participantes no nosso estudo, entretanto, apontam que os benefícios da cirurgia suplantam possíveis vantagens do parto vaginal, por exemplo, uma recuperação mais rápida e menos sofrida. A dor do pós-operatório da cesárea é representada como algo "tranquilo", que pode ser minimizado com a utilização de medicamentos: trata-se de uma dor do início (sua causa) ao fim (seu tratamento) controlada pela tecnologia.

Não senti dor, não senti nada porque eu estava à base de remédio, né? A médica deixa prescrito a medicação que a paciente vai tomar. Então assim que passou a anestesia eles já vieram como todos os remédios que eu precisava tomar. Depois quando eu cheguei em casa, eu comprei todos os remédios de novo, ainda tomei quase uns dez dias de remédio, né? Porque eram caixas de remédios, duravam mais ou menos uns dez dias. Não sentia dor, não sentia nada. Então a minha recuperação foi excelente. (Ana)

Foi uma beleza. O parto cesáreo também foi bom. Não doeu muito igual falaram que ia doer. (Silvia)

Não senti nada. Dores, todo mundo fala: 'Ah, cesárea é ruim'. Eu não senti dor, quando eu cheguei em casa eu fazia tudo. (Raquel)

\section{Integridade corporal}

Em muitas falas, o parto vaginal aparece como ameaça à integridade do corpo, como uma "agressão", uma "brutalidade”, visão que, muitas vezes, compartilham com o obstetra. 
Eu nunca quis ter parto normal, porque eu acho, eu penso que é uma coisa, assim. Eu acho que é uma agressão muito forte. Eu não queria passar por essa experiência. Eu tinha medo. (Mariana)

Por ele [obstetra] não existia mais o parto normal, porque ele acha que é um absurdo o parto normal, uma brutalidade. Ele só faz cesárea mesmo. (Tatiana)

O parto vaginal deixa sequelas no corpo, conforme enfatizam algumas mulheres. Funções excretórias e sexuais são ameaçadas, seja pela passagem do bebê pela vagina, seja pela manipulação médica do períneo. Iatrogenias derivadas de intervenções médicas no parto vaginal muitas vezes são confundidas com agressões do parto em si, fazendo com que as mulheres acreditem ser esse modo de parir mais deletério para o corpo feminino (Diniz \& Chacham, 2006).

A maioria das mulheres que eu conheço, que fez parto normal, teve que fazer operação de bexiga depois, além do períneo. (Ana)

E a desvantagem do [parto] normal é que você pode ficar com uma incontinência urinária. (Odete)

Um troço horrível. Imagina chegar e cortar com bisturi? [episiotomia] E depois como é que fica? Não volta ao normal. (Daniela)

Medo eu tenho das duas, né? Porque a outra [parto vaginal] também tem que cortar. (Beatriz)

Em um parto vaginal, a episiotomia é vista como um procedimento necessário, um modo de mitigar o "estrago", e o corte na região genital pode ser mais assustador do que o corte da cesárea. Normas sexuais falocêntricas e genitalocêntricas promovem uma espécie de conflito de interesses entre o bebê e o parceiro sexual. Nesse sentido, a cesariana pode representar um arranjo sociotécnico que aprofunda a desvinculação sexualidade/ reprodução, ao designar territórios corporais diferentes para essas atividades.

Quando ele é grande, o estrago é maior, né? A gente brincava, sempre falava do tamanho, que estava muito grande, a médica até brincou um dia, falou assim: 'olha, do tamanho que ele está eu acho que o seu marido também não vai gostar que seja normal'. (Carla)

Ao contrário do parto vaginal, com o aprimoramento das tecnologias e técnicas cirúrgicas, a cesárea seria algo pouco "agressivo", deixaria poucas ou mesmo nenhuma marca no corpo. A ausência de marcas corporais após a maternidade parece ser valorizada entre as mulheres, que não querem ter em seus corpos a marca da maternidade, diferentemente das mulheres de classes populares estudadas por Paim (1998), para quem tais marcas corporais são apreciadas ao registrar a função social materna, "Eu não tive problema nenhum, nenhum. Hoje em dia nem a marca de cesárea aparece direito. Só foram três pontos que ela deu, porque ela faz ponto de cirurgia plástica” (Ana).

O "corta e costura" da cesárea é naturalizado. Os sentidos do procedimento como cirurgia são esmaecidos, parece que "não estava acontecendo nada”: "corta”, "abre”, "tira” "costura”; é "light”, "rápido", "tranquilo”. O estilo de pensamento de uma cesárea simples, 
rápida e bonita, difundido entre os obstetras brasileiros (Nakano, Bonan, \& Teixeira, 2016) parece contagiar as ideias das mulheres acerca da cirurgia.

Então, assim, quem olha parece que realmente não estava acontecendo nada. Simplesmente estão me abrindo, estão me costurando, estão tirando. (Eliane)

A gente entra, toma a anestesia, aí corta, o neném nasce rapidinho, daqui a pouco tá no quarto. Eu nem vi passar a anestesia. É muito rápido! Quando você vê, já nasceu. (Helena)

A banalização das intervenções cirúrgicas sem as clássicas indicações médicas no Brasil não é exclusividade do universo da cesariana. Encontra-se um aumento expressivo de cirurgias estéticas, sobretudo entre mulheres, que, além de uma preocupação com a beleza, carrega múltiplos sentidos - acesso ao consumo, mobilidade social, competitividade no mercado de trabalho e na economia neoliberal da libido (Edmonds, 2007) - e reflete uma crescente permeabilidade do corpo feminino a intervenções biomédicas.

\section{Riscos de adoecimento e de morte}

O trabalho de parto e o parto são representados como eventos perigosos que acarretam ameaças à saúde, em especial, riscos de adoecimento ou morte do bebê. A saúde do bebê é componente importante das ponderações envolvidas na eleição do modo de parturição. As histórias de nascimentos por cesárea são geralmente lineares, descomplicadas, contrastando com relatos de trabalhos de parto e partos vaginais que são muitas vezes dramatizados.

Ela [irmã $]$ não teve condições e o médico deixou passar muito tempo. Minha sobrinha engoliu líquido amniótico na hora do parto. Quando foi fazer parto cesáreo, fez tudo correndo porque ela já estava com o cordãozinho enroscado no pescoço, ela teve até um corte aqui no supercílio, então foi bem traumático. (Karina)

Na percepção das mulheres, os riscos de uma intervenção cirúrgica - medicamente criados - são calculados e administrados; aqueles de um parto fisiológico são imprevisíveis e incontroláveis, daí a percepção de que a cirurgia é mais segura. A anestesia é a única intervenção médica que gera temores, mas no balanço de riscos e benefícios, ela não assombra as mulheres como um parto ditado pelos processos fisiológicos, visto como interminável e temerário, "A única coisa que eu tenho medo da cesariana é da anestesia. Eu já tinha passado por ela uma vez e a minha segunda experiência com anestesia foi ainda melhor do que a primeira, a primeira foi pior" (Beatriz).

O controle médico e tecnológico do corpo, da saúde e dos processos reprodutivos é uma disposição incorporada ao longo da vida das mulheres pesquisadas, no processo de socialização. "Sempre me cuidei muito", atestam, e na gravidez os cuidados são intensificados, visando também à saúde do feto. A qualidade da assistência pré-natal e a segurança da gestação estão intimamente associadas à quantidade de ultrassonografias, exames de sangue e outras tecnologias de vigilância da gravidez, além de complementos alimentares, dietas e exercícios. 
É, eu ia uma vez por mês à consulta. Fazia todos os exames. Fazia exame de sangue, de urina, ultras, vários exames. (Fabiana)

Tinha uma nutricionista me controlando, fiz pilates. Então assim, eu digo assim, que eu me cuidei mais. (Iara)

Os exames complementares e de imagem permitem saltar o corpo, prescindir dos sinais que ele emite sobre o bem-estar do bebê. Tecnologias visuais propiciam um conhecimento mais objetivo sobre o desenvolvimento fetal intrauterino, o corpo pode enganar.

Sonar para escutar o bebê. você escuta, mas não vê. A gente trabalha muito com a visão. Então só escutar a gente não sabe se está tudo bem, se está para lá, está para cá, mexendo. Com a ultra é diferente, na ultra você sai mais feliz. (Luisa)

A expectativa da produção do "bebê perfeito", a ideia de que o feto está, não em segurança, mas sim em perigo no corpo da mãe, e a responsabilização das mulheres por resultados negativos para o feto (Carter, 2010) - reforçadas pelos discursos dos obstetras de incompetência do corpo feminino, como se observa em expressões como "não tem passagem", "não tem dilatação" (Cherniak \& Fisher, 2008) - contribuem para a ideia de que o parto vaginal, de fato, é destinado a poucas (Martin, 1987/2006), "Porque com 7 meses, 6 meses... a obstetra disse que talvez eu não conseguisse ter parto normal porque eu não tinha passagem. A minha pelve era muito estreita" (Fabiana).

Assim, deve-se controlar o corpo na gestação e no momento do nascimento (Carter, 2010), antecipando-se a possíveis problemas no momento do parto, percebido como arriscado para a integridade e a vida da mulher e do bebê. Para controlá-lo, é necessário um ambiente apropriado, com técnicos e tecnologias.

Quando você se vê dentro de um hospital, você se sente amparada: Bom, se acontecer coisa mais forte, tem profissionais habilitados para isso. Em casa, por mais que tenha profissionais lá da área da saúde, mas não sei, não tem a mesma aparelhagem, é psicológico. Porque a modernidade nos dá isso e, em casa, não tem. (Tânia)

Portanto, a lógica intervencionista do pré-natal é também transposta para o momento do nascimento. Esse se tornou, por assim dizer, mais um item em um pacote de intervenções que fazem parte de um modelo medicalizado-mercantilizado de assistência à saúde. Em tal modelo, o conhecimento técnico-científico tornou-se uma ferramenta do comércio do parto (Cardoso \& Barbosa, 2012), assim como do pré-natal.

\section{A estética do parto}

A A A preferência das mulheres por ambientes limpos, assépticos e cercados de tecnologias, como um centro cirúrgico, aparece como uma tentativa de controle das expressões estéticas do parto. A imagem da criança, que nasce em meio de panos sujos de sangue, mecônio, líquidos e excrementos não combina com uma cultura que valoriza a higiene e a limpeza. Vários aspectos da vida da mulher "civilizada" envolvem a assepsia do corpo, o que se contrapõe à imagem do parto vaginal e suas secreções naturais. 
Assim, a estética de um parto vaginal incontinente e "sujo" não condiz com a mulher "civilizada”, e é algo que não se quer nem mesmo assistir, "Ah, deve ser um negócio horroroso. Cruz credo! Não quero não [assistir a um parto vaginal]" (Odete).

No parto vaginal a mulher pode ficar horas "fazendo força": trata-se de um corpo "descontrolado", que tem que se "esticar", algo "apavorante" tanto para a integridade corporal quanto esteticamente:

Não, ficar fazendo força. Sabe lá quanto tempo o neném vai demorar para nascer. (Helena)

Não, assim. Porque como é que a gente pode esticar tanto daquele jeito? Sai uma criança de dentro de você, é uma coisa meio que me apavora. (Patrícia)

Por vezes, o nascimento em si, seja via parto vaginal ou cesárea, aparece como um evento esteticamente desagradável e o bebê, um ser humano que nasce "sujo", "imundo".

Porque se você parar e pensar, eu acho que para um homem, por mais que você fale que é o maior barato ele ver o filho dele nascendo, é muito agressivo [o nascimento]. Ele está vendo um ser humano aberto, e um chegando todo sujo, imundo e tal. Eu acho que nem todo homem está preparado para assistir isso não. (Eliane)

Daí a gente fica olhando os partos. É horrível de se ver. Nem um, nem outro. Nem normal, nem cesárea. (Laura)

Na fala de outras mulheres, a cesárea aparece como esteticamente "light" e "legal". A Esta prática também faz parte de um contexto sociocultural de exposição da intimidade e valorização da visualização dos eventos, fazendo parte de uma sociedade do exposição da intimidade na cesárea não é um problema, ela pode ser filmada, fotografada, é Um nascimento que pode ser retratado esteticamente, pois não aparece "muita coisa" - fluidos e tecidos do corpo humano - e os profissionais têm o cuidado de "tampar tudo", para não aparecer sangue.

É. Ele [marido] gravou. Até eu assisti. Depois eu assisti, foi bem light, porque eles tampam tudo. Você só vê o neném saindo e tal, aí não vê uma coisa, não vê cortando, não vê sangue, né? Aí eu acho que foi legal. (Odete)

A contenção das atividades corporais surge como algo que expressa civilidade (Elias, 1939/1994), enquanto o parto vaginal é uma prática que remete ao selvagem, ao primitivo. As práticas que não envolvem medicalização são vistas como não científicas, supersticiosas e atrasadas (Jordan, 1993). Assim, parir hoje seria algo mais difícil e mais arriscado, para a mulher e o bebê, e, esteticamente, não condiz com a "mulher civilizada", que pode usufruir das tecnologias médicas e não médicas para "apagar” os vestígios de sua condição biológica: "Então parto normal nunca passou pela minha cabeça, nunca. Foi uma opção [a cesárea]. Estou falando, parto normal é muito bom para índio, vaca, cabra que está no meio do mato, eu estou fora" (Ana). 
Assim, paradoxalmente, essas mulheres naturalizam o nascimento e a maternidade, mas apartam-se de sua condição biológica, buscando diferenciar-se do "índio", da "vaca", da "cabra". Isto é, do que se constituiu como "natureza" (Roberts, 2012), afastando-se de seu corpo biológico na tentativa de exercer um controle sobre ele e a vida.

\section{O tempo social e produtivo}

O momento do nascimento deve ser controlado, organizado e planejado para se adequar à vida das "mulheres de hoje". O planejamento da vida reprodutiva aparece como relevante para as mulheres pesquisadas, para quem a gravidez e o parto devem ser previsíveis e planificados. Assim, a cesariana, pela possibilidade de data marcada, aparece como situação ideal e vantajosa para as mulheres: "Da cesárea, o bom assim que hoje eu vejo que marca um dia e um horário que você tem que se programar" (Tânia).

Cherniak e Fisher (2008) argumentam que o índice de cesariana cresceu juntamente com o aumento da escolaridade das mulheres até o nível superior, com sua participação na força de trabalho, na vida pública e política. Nesse sentido, em geral, os nascimentos, assim como as gestações, são planejados dentro de um contexto conjugal, familiar, financeiro e profissional favorável. Afinal, a mulher "hoje em dia" estuda, trabalha - a maioria ainda acumula duplas jornadas de trabalho -, participa da vida social e tem que racionalizar o seu tempo.

Muita gente prefere a cesárea pela facilidade de marcação, porque hoje em dia a mulher trabalha, a mulher tem várias obrigações, então assim muitas mulheres também optam. (Luisa)

Ai! Foi ótima! Porque foi planejada, a gente se programou. Eu e meu marido. A gente se programou. Calculamos. Eu trabalho numa creche da prefeitura e eu calculei o tempo certo pra poder ficar em casa. Foi tudo assim. Deu tudo certo. Conforme a gente pensou. (Nadia)

Não ia ter quem ficasse com ela [filha mais velha] para mim, aí eu optei por agendar o parto por causa disso, para programar melhor quem ia ficar com ela, quem ia cuidar dela enquanto eu estivesse lá? (Valéria)

Para Giffin (2002), no âmbito da discussão das relações de gênero e dos direitos reprodutivos, as condições reais para o exercício da maternidade não foram prioridade. O trabalho com vínculos incertos e precários, que atinge, sobretudo, as mulheres, as predispõe a um receio de perder o emprego e o controle sobre sua vida (Ávila, 2004; Hirata, 2011). Uma das possíveis consequências pode ser o retorno precoce das mulheres à vida laboral e/ou a intensificação do ritmo de trabalho, como forma de compensar o período de afastamento para o puerpério, o que pode aumentar a necessidade de planejamento do tempo, por parte das mulheres. Lupton e Schmied (2012) apontam a necessidade de controle imputada às mulheres nas sociedades contemporâneas: elas precisam controlar sua fecundidade, planejar seus filhos, equacionar sua vida profissional.

A cesárea marcada com antecedência é um arranjo social e institucional que aparece como uma vantagem por possibilitar a busca da data mais conveniente também para o companheiro, os pais e outros familiares. Portanto, o nascimento hospitalar, cercado de 
intervenções médicas e cirúrgicas, não elimina simplesmente o componente familiar do parto, mas o reestrutura profundamente. Nesse aspecto, não se pode falar da perda da dimensão social e familiar no evento do nascimento, mas de um novo sentido atribuído a este fenômeno como algo previsível, controlado e planejado dentro de um novo contexto social na vida das mulheres pesquisadas e famílias: "Estavam todos comigo dentro do quarto. Inclusive quando eu voltei da cesárea, estavam, todos os 40 [familiares], dentro do quarto" (Gabriela).

As mulheres não têm que lidar apenas com as próprias necessidades, sejam relacionadas ao trabalho ou à vida familiar. Há que conciliar suas próprias questões com as necessidades de organização do hospital e do médico; a cesariana marcada é naturalizada como a forma ideal de concertação entre os tempos e as demandas das mulheres, dos médicos e das instituições hospitalares.

Ele já tinha dado a opção da cesárea por conta do agendamento do hospital, que ele disse que era complicado. Se fosse normal ele falou que não tinha vaga quando chegava, e [que] marcado era melhor porque já estava tudo agendadinho, tudo estaria nas mãos dele. Aí isso foi na primeira consulta. (Tânia)

Eu decidi que ia ser cesárea porque logo ele [o obstetra] ia viajar... (Rita)

Não, ela [obstetra] até que aceitou numa boa [marcar a cesárea]. Porque para médicos às vezes é melhor. Porque é marcadinho direitinho o dia, a hora, data. Tudo para ela. Assim, ela tinha muitos pacientes, então ela tinha medo da pessoa correr risco. Da pessoa estar passando mal, ligar para ela, ela ter que largar às vezes uma paciente e ter que correr para fazer um parto. (Patrícia)

A conveniência dos profissionais de saúde, especialmente os médicos, associada aos seus interesses mercantis, assim como das instituições hospitalares, não podem ser minimizados na produção da prática da cesariana. Numa sociedade capitalista, a cesárea significa maior produtividade, pois pode ser realizada em menor tempo e maior lucratividade, pelo aumento das despesas hospitalares (Cardoso \& Barbosa, 2012).

\section{Considerações finais}

A crescente prática da cesariana pode ser entendida como parte de um contexto sociocultural, econômico e político em que se valoriza, entre outros fatores, a ideia de controle tecnológico do corpo e da vida e um melhoramento de si (Rose, 2013). Esse controle é perpassado por forças materiais e por normas sociais que regulam todas as esferas e dimensões da vida contemporânea, é exercido em redes de interações entre mulheres, familiares, profissionais, objetos tecnológicos (médicos e não médicos), instituições hospitalares e seguros de saúde.

Entre as mulheres participantes do estudos - mulheres urbanas pertecentes às classes de maior renda e escolaridade e usuárias de planos de saúde - preponderam os sentidos da cesárea como uma forma de nascimento que possibilita o controle da dor, da integridade genital, das expressões estéticas, dos riscos e do tempo, expressando uma cultura em que o corpo se tornou um objeto a ser controlado, aprimorado e ativamente 
modulado pelas tecnologias, e, mais, permeável a elas. Tais sentidos são fortalecidos e construídos juntamente com o discurso sutil ou explícito dos profissionais, figuras com as quais as mulheres indicam compartilhar significativos vínculos de confiança. Por via do poder econômico, da identificação ideológica e de pertencimento de classe, as mulheres desenvolvem laços expressivos com seus obstetras. Uns colocam-se no lugar dos outros: compartilham, em grande medida, valores e desejos legítimos em um sistema ideológico individualista e utilizam a tecnologia a serviço das aspirações comuns.

A responsabilidade de cuidar de si e a escolha pelas intervenções na gestação e parto são assumidas positivamente pelas mulheres como uma questão de protagonismo e direito, no âmbito do controle dos seus corpos e de sua saúde. Contudo, conforme Rose (2013), a biopolitica contemporânea, a política da própria vida, implica a noção de que o sujeito ativo é obrigado a escolher. Direitos e deveres, protagonismo e passividade, volição e obrigação parecem não se contrabalançar, mas se confundir. Na obrigação moral da gestão do parto e nascimento - a fim de produzir um bebê saudável, segundo os imperativos da maternidade, mas também de manter o desempenho laboral, social, sexual - elas são compelidas a escolher um nascimento controlado (Bryant, Porter, Tracy, \& Sullivan, 2007), em um ambiente controlado. O controle de si - corpo, saúde, tempo, produtividade - caracteriza, portanto, uma biopolítica do self(Rose, 2013).

As fronteiras entre coerção e consentimento ficam borradas quando se deve assumir a responsabilidade moral por sua própria saúde (Rose, 2013). O controle de si, do próprio corpo e da própria vida não é imposto meramente de fora para dentro, mas engendra dispositivos normativos incorporados, como o discurso da autonomia individual e da autogovernabilidade - do "direito de escolha" - com relação aos corpos (Foucault, 1976/1985).

Para McCallum (2005), em muitas ocasiões, a eleição da mulher por uma cesárea é uma escolha ideologizada, porque é permeada por um discurso sociocultural de que a cirurgia é moderna e indolor. Embora possa se considerar uma dimensão na qual escolhas/ decisões/interesses individuais - de profissionais ou de mulheres - jogam um papel, a prática da cesárea não está desconectada de um contexto macrocultural e macrossocial, no qual normas compartilhadas e relações de dominação constrangem ou delimitam as possibilidades para as práticas individuais e coletivas (Riscado, Jannotti, \& Barbosa, 2016). Um estudo discute que não se trata apenas da escolha da cirurgia em si, como técnica de dar à luz, mas quando muitas mulheres se decidem pela cesárea, almejam também um parto que contenha cenários, artefatos, ganhos e benefícios sociais, afetivos e políticos diversos (Nakano, Bonan, \& Teixeira, 2015).

Assim, à luz dos resultados de nossa pesquisa, o controle sobre o corpo e a vida na experiência da gestação e parto, e em especial no âmbito da cesárea, não significa nem superação nem submissão às dinâmicas de dominação. A normalização da cirurgia cesariana como modo de fazer nascer (Nakano et al., 2016) parece traduzir formas de viver e formas de controle sobre o fluxo da vida emergentes nesta fase civilizatória do neoliberalismo e da biopolítica de populações, que agora não tem como escopo somente a espécie, mas também o individuo. Esse indivíduo deve ser um empreendedor de si mesmo e, portanto, deve estar no controle; a ele é outorgado o direito/obrigação de ser ativo, produtivo, eficaz, autônomo, bem sucedido (Dardot \& Laval, 2016). 
No contexto de intensificação do neoliberalismo, o incremento da prática da cesárea parece também um caso emblemático de mercantilização da saúde e da vida como um todo. Os profissionais, as instituições e as próprias mulheres estão inseridos nessa lógica mercantil, e a valorização da ciência e da tecnologia faz parte de uma ideologia de consumo, que engloba o mercado do pré-natal e do parto (Wendland, 2007). A cesárea, entendida como um procedimento que elimina a dor, que protege o corpo dos efeitos deletérios do parto vaginal, que mitiga riscos, que é esteticamente viável e otimiza os tempos (produtivo e reprodutivo), assume contornos de um objeto de consumo, disponível a quem puder custeá-lo (Yasle et al., 2001). Para além da própria via de parto, o evento do nascimento com a presença da família, filmagens, fotografias, entre outras coisas, é transformado numa significativa celebração do momento de transição para a maternidade (O’Douguerty, 2013).

Em suma, a cesariana desponta como uma prática de fazer nascer em que está contido um ideário de controle tecnológico do corpo e da vida, seja dos processos corporais em sua dimensão performática e fisiológica, seja da vida, isto é, do corpo no tempo e no ambiente físico e cultural. Controle esse que é perpassado por forças materiais e dispositivos normativos incorporados que incitam um investimento produtivo sobre o corpo: o corpo do biopoder e da biopolítica, que deve ser cuidado e maximizado em suas potencialidades e gerido em todos os seus detalhes (Foucault, 1976/1985); o corpo da biomedicalização, cada vez mais dependente das inovações tecnocientíficas, inserido nas lógicas econômicas do capitalismo tardio, neoliberal e global e sobre o qual se impõe como regime de verdade sobre a "vida em si mesma" (Clarke et al., 2010; Rose, 2013).

Em que pese a limitada problematização, no presente artigo, de alguns elementos que também compõem o ideário do controle sobre o parto e o nascimento - como os riscos ou resultados não esperados com a cirurgia ou a reiteração de papéis de gênero (mulher deve estar sempre bela e disponível, para o parceiro, a comunidade e o trabalho produtivo) vemos que as falas das mulheres levantam nuances dessas dimensões. Portanto, alertamos que futuras pesquisas estejam atentas a elas.

\section{Nota}

1 Bonan, C. (2013). Itinerários terapêuticos e a construção da decisão sobre o parto cesáreo. IFF/Fiocruz; Relatório de Pesquisa (mimeo). 


\section{Referências}

Almeida, N. A. M., Medeiros, M., \& Souza, M. R. (2012). Perspectiva de dor de parto normal de primigestas no período pré-natal. Texto Contexto e Enfermagem, 21(4), 819-827.

Ávila, M. B. (2004). Vida cotidiana e o uso do tempo pelas mulheres. In Anais do VIII Congresso Luso-Afro-Brasileiro de Ciências Sociais. Coimbra, PT: Centro de Estudos Sociais, Universidade de Coimbra. Recuperado de https://www.ces.uc.pt/lab2004/inscricao/pdfs/ painel29/MariaBetaniaavila.pdf

Barros, A. J., Santos, I. S., Matijas evich, A., Domingues, M. R., Silveira, M., Barros, F. C., \& Victora, C. G. (2011). Patterns of deliveries in a Brazilian birth cohort: almost universal cesarean sections for the better-off. Revista de Saúde Pública, 45(4), 635-643.

Beogo, I., Rojas, B. M., \& Gagnon, M. P. (2017). Determinants and materno-fetal outcomes related to cesarean section delivery in private and public hospitals in low- and middle-income countries: a systematic review and meta-analysis protocol. Bio Med Central, 6(1), 5-8.

Bryant J., Porter M., Tracy, S. K., \& Sullivan E. A. (2007). Caesarean birth: consumption, safety, order, and good mothering. Soc., Sci., Med., 65, 1192-1201.

Cardoso, J. E. \& Barbosa, R. H. S. (2012). O desencontro entre desejo e realidade: a "indústria" da cesariana entre mulheres de camadas médias no Rio de Janeiro, Brasil. Physis, 22(1), 35-52. Carneiro, R. G. (2015). Cenas de parto e políticas do corpo. Rio de Janeiro: Fiocruz.

Carter, S. K. (2010). Beyond control: body and self in women's childbearing narratives. Sociology of Health \& Illness, 32(7), 993-1009.

Cesar, J. A., Mano, P. S., Carlotto, K., Gonzalez-Chica, D. A. \& Memdoza-Sassi, R. A. (2011). Público versus privado: avaliando a assistência à gestação e ao parto no extremo sul do Brasil. Revista Brasileira de Saúde Materno Infantil, 11(3), 257-263.

Cherniak, D. \& Fisher, J. (2008). Explaining obstetric interventionism: Technical skills, common conceptualisations, or collective countertransference? Women's Studies International Forum, 31, 270-277.

Clarke, A., Fishman, J., Fosket, J., Mamo, L., \& Shim, J. (2010). Biomedicalization: technoscience, health and illness in US. Durham, NC: Duke University Press.

Dardot, P. \& Laval, C. (2016). A nova razão do mundo. Ensaio sobre a sociedade neoliberal. São Paulo: Boitempo.

Diniz, S. G. \& Chacham, A. S. (2006). O "corte por cima" e o "corte por baixo": o abuso de cesáreas e episiotomias em São Paulo. Questões de Saúde Reprodutiva, 1(1), 80-91.

Domingues, R. M. S. M., Dias, M. A. B., Nakamura-Pereira, M., Torres, J. A., d'Orsi, E., Pereira, A. P. E. et al. (2014). Processo de decisão pelo tipo de parto no Brasil: da preferência inicial das mulheres à via de parto final. Cadernos de Saúde Pública, 30(Supl.), 101-116.

Edmonds, A. (2007). "The Poor Have the Right To Be Beautiful": Cosmetic Surgery in Neoliberal Brazil. The Journal of the Royal Anthropological Institute, 13(2), 363-381.

Elias, N. (1994). O Processo Civilizador: uma história dos costumes (R. Jungmann, Trad.). Rio de Janeiro: Jorge Zahar. (Original publicado em 1939)

Foucault, M. (1985). História da Sexualidade I: a vontade de saber (M. T. C. Albuquerque \& J. A. G. Albuquerque, Trad., $7^{\mathrm{a}}$ ed.). Rio de Janeiro: Graal.

Giffin, K. (2002). Pobreza, desigualdade e equidade em saúde: considerações a partir de uma perspectiva de gênero transversal. Cadernos de Saúde Pública, 18(Supl.), 103-112.

Hirata, H. (2011). Tendências recentes da precarização social e do trabalho: Brasil, França, Japão. Caderno CRH, 24(1), 15-22.

Hotimsky, S. N., Rattner, D., Venancio, S. I., Bógus, C. M., \& Miranda, M. M. (2002). O parto como eu vejo... ou o parto como eu desejo? Expectativas de gestantes, usuárias do SUS, acerca do parto e da assistência obstétrica. Cadernos de Saúde Pública, 18(5), 1303-1311. 
Jordan, B. (1993). Birth in Four Cultures. A crosscultural investigacion of childbirth in Yucatan, Holland, Sweden, and the United States. Long Grove, IL: Waveland press.

Leal, M. C., Silva, A. A. M., Dias, M. A. B., Gama, S. G. N., Rattner, D., Moreira, M. E., Theme Filha, M. M. et al. (2012). Birth in Brazil: national survey into labour and birth. Reprod Health, 9(15), 15.

Lupton, D. \& Schmied, V. (2012). Splitting bodies/selves: women's concepts of embodiment at the moment of birth. Sociology of Health \& Illness, $X X(\mathrm{X}), 1-14$.

Martin, E. (2006). A mulher no corpo: uma analise cultural da reprodução (J. Bandeira, Trad.). Rio de Janeiro: Garamond. (Original publicado em 1987)

McCallum, C. (2005). Explaining caesarean section in Salvador da Bahia, Brazil. Sociology of Health \& Illness, 27(2), 215-242.

McCallum, C. \& Reis, A. P. (2006). Re-significando a dor e superando a solidão: experiência do parto entre adolescentes de classes populares atendidas em uma maternidade pública em Salvador, Bahia, Brasil. Cadernos de Saúde Pública, 22(7), 1483-1491.

Minayo, M. C. S. (2010). O desafio do conhecimento: pesquisa qualitativa em saúde (12 ${ }^{\mathrm{a}} \mathrm{ed}$.). São Paulo: Hucitec.

Nakano, A. R., Bonan, C., \& Teixeira, L. A. (2015). A normalização da cesárea como modo de nascer: cultura material do parto em maternidades privadas no Sudeste do Brasil. Physis, 25(3), 885-904.

Nakano, A. R., Bonan, C. \& Teixeira, L. A. (2016). Cesárea, aperfeiçoando a técnica e normatizando a prática: uma análise do livro Obstetrícia, de Jorge de Rezende. História, Ciências, Saúde, 23(1), 155-172.

O'Douguerty, M. (2013). Plot and irony in childbirth narratives of middle-class Brazilian women. Medical Anthopology Quaterly, 27(1), 43-62.

Paim, H. H. S. (1998). Marcas no Corpo: gravidez e maternidade em grupos populares. In L. F. D. Duarte \& O. F. Leal (Orgs.), Doença, sofrimento, perturbação: perspectivas etnográficas (pp. 31-47). Rio de Janeiro: Editora Fiocruz.

Pereira, R. R., Franco, S. C., \& Baldin, N. (2011a). Representações sociais e decisões das gestantes sobre a parturição: protagonismo das mulheres. Saúde e Sociedade, 20(3), 579-589.

Pereira, R. R., Franco, S. C., \& Baldin, N. (2011b). A dor e o protagonismo da mulher na parturição. Revista Brasileira de Anestesiologia, 61(3), 382-388.

Riscado, L.C., Jannotti, C. B., \& Barbosa, R. H. S. (2016). A decisão pela via de parto no Brasil: temas e tendências na produção da Saúde Coletiva. Texto Contexto e Enfermagem, 25(1), e3570014.

Roberts, E. F. S. (2012). Scars of nation: surgical penetration and the ecuadorian state. The journal of the Latin American and Caribbean anthropology, 17(2), 215-237.

Robson, M. S. (2001). Can we reduce cesarean section rate? Best Practice \& Research Clinical. Obstetrics \& Gynaecology, 15(1), 179-194.

Rose, N. (2013). A política da própria vida. Biomedicina, poder e subjetividade no século XXI (P. F. Valerio, Trad.). São Paulo: Paulus.

Sanabria, E. (2010). From Sub- to Super-Citizenship: sex hormones and the body politic in Brazil. Ethnos, 75(4), 377-401.

Spink, M. J. \& Medrado, B. (2013). Produção de sentido no cotidiano: uma abordagem teóricometodológica para análise das práticas discursivas. In M. J. Spink (Org.), Práticas discursivas e produção de sentidos no cotidiano (pp. 22-41). São Paulo: Edição Virtual. 
Victora, C. G., Aquino, E. M., Carmo Leal, M., Monteiro, C. A., Barros, F. C., \& Szwarcwald, C. L. (2011). Maternal and child health in Brazil: progress and challenges. Lancet, 377(9780), 1863-1876.

Wendland, C. L. (2007). The vanishing mother: Cesarean section and "evidence-based obstetrics". Med Anthropol Q., 21(2), 218-233.

World Health Organization - WHO. (2015). Statement on caesarean section rates. http:// apps.who.int/iris/bitstream/10665/161442/1/WHO_RHR_15.02_eng.pdf?ua=1.

Yasle, M. E. H. D., Yazle, R. J. S., Mendes, M. C., Patta, M. C., Marcolin, A. C., \& Azevedo, G. D. (2001). Incidência de cesáreas segundo fonte de financiamento da assistência ao parto. Revista de Saúde Pública, 35(2), 202-206.

\section{LIANA RISCADO \\ https://orcid.org/OOOO-0001-7352-4882}

Pesquisadora autônoma e psicóloga clínica. Doutora em Ciências pelo Instituto Nacional de Saúde da Mulher, da Criança e do Adolescente Fernandes Figueira, Fundação Oswaldo Cruz.

Endereço: Av. Rui Barbosa 716, Flamengo. Rio de Janeiro, RJ, 22250-020.

E-mail: liana.carvalho.124@gmail.com

\section{CLAUDIA BONAN}

\section{http://orcid.org/0000-0001-8695-6828}

Médica e Pesquisadora, Instituto Nacional de Saúde da Mulher, da Criança e do Adolescente Fernandes Figueira/Fiocruz. Rio de Janeiro/RJ.

E-mail: chonan@globo.com

\section{REGINA SIMÕES-BARBOSA}

https://orcid.org/O000-0002-1161-7220

Psicóloga. Professora e Pesquisadora no Instituto de Estudos em Saúde Coletiva, Universidade Federal do Rio de Janeiro.

E-mail: reginacasa@gmail.com

\section{ANDREZA RODRIGUES \\ https://orcid.org/0000-0002-1873-5828}

Enfermeira Doutora em Ciências pelo Instituto Nacional de Saúde da Mulher, da Criança e do Adolescente Fernandes Figueira, Fundação Oswaldo Cruz. Professora Adjunta na Escola de Enfermagem Anna Nery, Universidade Federal do Rio de Janeiro. Rio de Janeiro/RJ.

E-mail: andrezaenfermeira@gmail.com 


\begin{tabular}{|c|c|}
\hline Histórico & $\begin{array}{l}\text { Submissão: 09/02/2019 } \\
\text { Revisão: 23/6/2020 } \\
\text { Aceite: 24/7/2020 }\end{array}$ \\
\hline Contribuição dos autores & $\begin{array}{l}\text { Concepção: LR; CB; RSB. } \\
\text { Coleta de dados: LR; CB; AR. } \\
\text { Análise de dados: LR; CB; RSB; AR. } \\
\text { Elaboração do manuscrito: LR; CB; RSB; AR. } \\
\text { Revisões críticas de conteúdo intelectual } \\
\text { importante: LR; CB; RSB; AR. } \\
\text { Aprovação final do manuscrito: LR; CB; RSB; AR. }\end{array}$ \\
\hline Consentimento de uso de imagem & Não se aplica. \\
\hline Aprovação, ética e consentimento & $\begin{array}{l}\text { Apreciado e aprovado pelo Comitê de Ética em Pesquisa } \\
\text { do Instituto Fernandes Figueira/Fiocruz (CAAE } \\
\text { 36529714.2.0000.5269) }\end{array}$ \\
\hline Financiamento & $\begin{array}{l}\text { O presente trabalho foi realizado com apoio da } \\
\text { Coordenação de Aperfeiçoamento de Pessoal de Nível } \\
\text { Superior - Brasil (CAPES) - Código de Financiamento ool }\end{array}$ \\
\hline
\end{tabular}

